\title{
Consideration of impact assessment of vibrations for strength and compression in silty soils
}

\author{
Janusz Ukleja ${ }^{1, *}$ \\ ${ }^{1}$ Faculty of Civil Engineering and Architecture, Opole University of Technology, Katowicka 48, \\ 45-061 Opole, Poland
}

\begin{abstract}
Strength and deformation of soil are determined in laboratory tests through shear strength and compression tests. However they do not take into account the impact of dynamic vibration which can cause thixotropy or fluidization of soil. To allow for that, a method which modifies the course of laboratory tests has been proposed. It includes dynamic vibration into shear strength and compression tests of soil. It makes it possible to measure and classify the tested ground with respect to susceptibility to thixotropy caused by dynamic vibrations which lower strength parameters of water saturated silty soils. Earlier research of soil strength parameters tended to underestimate the impact of dynamic vibrations which sometimes constitute initiatory impulse for numerous landslides in rockmass, especially in flysch.
\end{abstract}

\section{Preface}

\subsection{Introduction}

Two physical and mechanical parameters decide about strength and deformation of soil: the first one being shear strength, the second one - soil compression. Shear strength is resistance of soil to static stress in the considered fragment. In order to determine shear strength, laboratory tests are held with intermediate shearing test apparatus or triaxial compression test apparatus, whereas soil compression is determined in oedometric tests. In the procedure of both the test types, a soil sample is made to reach its natural structure. The triaxial method reflects shearing conditions in the isotropic layer of high thickness, whereas the immediate shearing method additionally allows to reflect conditions found in narrow contact zones of soil layers of different characteristics, where landslides can be initiated. Results of the above mentioned tests are obtained with assumption of consistency or insignificant changes in the soil structure within the whole period of testing in a laboratory. They, above all, do not consider a possibility of changes in ground framework structure at

\footnotetext{
* Corresponding author: $\underline{\text { ukleja2012@gmail.com }}$
} 
the time of testing caused by dynamic impact. In site conditions the external dynamic impact can result from:

a) vehicles travelling on soil surcharge,

b) vibrations of machines and equipment,

c) vicinity of belt conveyor flights ( for instance in open-pit mines),

d) shooting or rockbust ( for instance in underground mining),

e) natural factors such as earthquakes or thunders and others.

The above mentioned factors caused by dynamic impact can significantly change stress conditions and form strength parameters of soil. It mainly considers soils of considerable content of silt fraction (silty soils), especially when they are found in water saturated environment. Dynamic vibrations can have multiple impact on changes in soil strength:

- increase in strength caused by self-thickening of soil can be observed in case of unsaturated coarse soils,

- in case of water saturated cohesive silty soils a phenomenon called thixotropy can occur. It causes a significant decrease in particle friction resulting in lessening or loosing contact strength, which is caused by pore pressure and results in transformation into liquid state,

- in case of water saturated non-cohesive soils with no drainage, liquefaction of soil can occur as a result of dynamic vibrations of cyclic load resulting in increase in pore water pressure, and in extreme cases to the extent when effective stress reaches zero.

The above discussed issues have partially been reflected in numerous publications, for example [1-7]. The test method described by Taslagy, Chan and Morgenstern [4 and 5] is equally worth consideration. They tested the effect of sand vibration [4]. The analysis was based on innovatory method of laboratory tests published in [5] in 2015. The idea of the solution has been referred to and used in this article.

\subsection{Characteristics of influence of dynamic impact on soil}

Soil vibrations caused by dynamic impact can initiate thixotropy in cohesive (silty) soils and liquefaction of non-cohesive soils. In non-cohesive soils liquefaction can be the result of vibrations in high water saturation conditions and lack of drainage. It is manifested by reduction of particle friction causing their mutual relocation. In this case we speak about quicksand occurring in sands and silty sands. It can be stopped by lowering water pressure in ground. In the case of cohesive soils, the framework of which is made of small particles with dominance of silt, long lasting structure disturbances can occur leading to changing its state to liquid. However, to make it happen, not only water saturation is needed, but also an impulse. This role can be taken by all sorts of vibrations. The changes are hardly reversible, sometimes impossible to reverse, despite ceasing of their initial reason.

Thixotropy consists in solation (into a liquid body of sol) of colloid saturated soils (small particles) from gelatinised state (gelatinous body) under the influence of quakes and vibrations or increase of pore water pressure (Fig. 1). Soils containing small particles of clay of colloidal sizes $(<0.0002 \mathrm{~mm})$ are characterised by thixotropy. It also occurs when the ground framework is partially composed of particles significantly bigger than colloids, for instance silt or fine sand. [7]. 
a) gelatinised state

b) liquefacted sol

1 -water

2 - solid particles

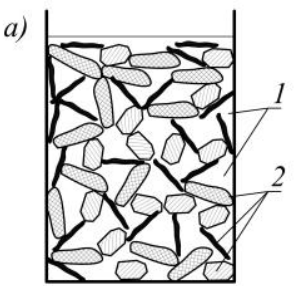

b)

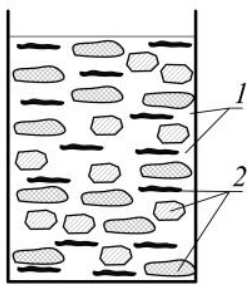

Fig. 1. Various forms of thixotropic structure.

Gelatinisation of soil is possible under the influence of mechanical stimuli when mineral particles in the solution get freedom of motion and become able to rotate. This phenomenon is partially reversible and the time of getting a stable state depends on the type of soil.

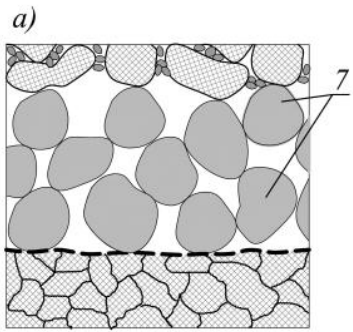

c)

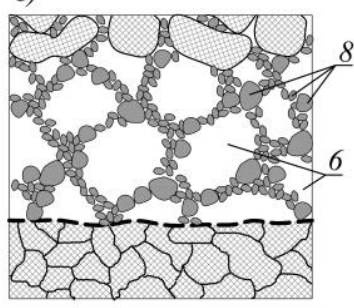

b)

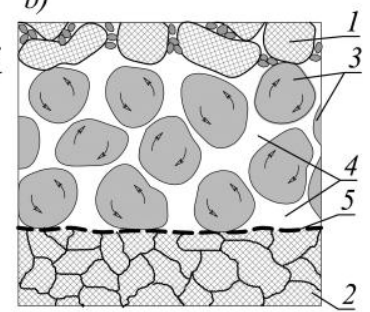

d)

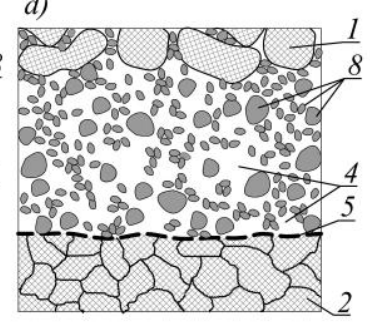

a) Coarse ground-stable state,

b) Coarse ground - under vibrations,

c) Fine silty soil - stable state

d) Fine silty soil - under vibrations.

\section{1-flysch \\ 2-rock-mantle \\ 3- soil grains - movable \\ 4-water \\ 5- slide zone limit \\ 6- pores (water and air) \\ 7- stable soil grains \\ 8- silty soil particles}

Fig. 2. Characteristic forms of soil sensitive to thixotropy and fluidization.

Second mutual clinging of neighbouring particles with their sharp edges is caused by forces of molecular and electrostatic attraction between them (Fig. 1a). Special susceptibility to thixotropy causing transition from firm to soft or even very soft state is observed mainly in silt, silty clay, sandy silt, sandy clay, silty sand, unwashed rock-mantle of all types of rock.

\subsection{Influence of thixotropy and fluidization on rock mass stability}

The phenomenon of thixotropy has major influence of ground parameters and, as a result, stability of rock mass. Decrease in ground strength can result in landslides initiated by vibrations, lasting longer than the vibrations themselves. It causes hazard of the rock mass stability loss in slopes and scarps or in ground under buildings [6]. However, to let that happen, the following favourable circumstances are necessary:

a) full water saturation of the potential slide layer of ground as a result of precipitation or rise of ground water level,

b) Simultaneous presence of dynamic stimuli, especially harmonic vibrations of given frequency and amplitude and duration, which make thixotropy or fluidization possible in the slide layer of ground,

c) Possible additional external load, for example with trees, wind, vehicles, etc.

Fig. 2 shows characteristic forms of soil structure sensitive to vibrations lessening or 
causing lack of friction among particles in the ground framework. Both the coarse soils (Fig. 2a and 2b) and the fine ones (Fig. 2c and 2d) can, in such conditions, become fluidised or undergo thixotropy caused by vibrations.

Sandy alluvia composed of smoothed grains, especially with addition of silt and clay are predestined to decrease in internal friction in their ground framework. This is caused by possibility of mutual rotation of individual grains (Fig. 2b). Silty soils of cellular structure (Fig. 2c) lose their apparent coherence to reach liquid state as a result of quakes Fig. 2d. Therefore it seems advisable to undertake laboratory tests of soils of similar structure to determine changes in their strength under the impact of dynamic vibrations.

Until now it was common to neglect these issues in laboratory tests despite their significance. Observations and analyses prove that the phenomenon appears to have considerable influence on stability and safety of numerous structures, such as scarps and slopes in open pit mines.

\section{Methods applied to determine soil strength}

\subsection{Immediate shearing test apparatus}

Coulomb interaction constitutes basis for determination of soil shear strength [7], however it does not take into consideration the impact of dynamic stimuli. As it results from this interaction, the amount of static stress constituting soil shear strength depends on friction resistance and cohesion:

$$
\tau_{f}^{\prime}=\sigma^{\prime} \cdot \operatorname{tg} \phi^{\prime}+c^{\prime}
$$

where: $\sigma^{\prime}$ - effective normal stress to the shear surface $\left(\sigma^{\prime}=\sigma-u\right)$,

$\sigma-$ normal stress to the shear surface,

$u$-water pressure in soil pores,

$\tau_{f}^{\prime}-$ resistance of the ground against static stress (when $\Delta u=0$ ),

$\phi^{\prime}$ - proper (effective) internal friction angle (when $\Delta u=0$ ),

$c^{\prime}$ - effective cohesion (when $\Delta u=0$ ).

\subsection{Oedometer}

To determine the rate of ground subsidence the module of ground compression $\mathrm{M}$ is used, determined from the following interaction:

$$
M_{o}, M=\frac{\Delta \sigma}{\varepsilon}=\frac{\Delta \sigma \cdot h}{\Delta h}
$$

where: $\quad M_{o}, M$ - oedometric module of primary compression, secondary,

$\Delta \sigma_{i}-$ increase in stress in the ground framework

$\varepsilon=\Delta h / h-$ relative deformation of ground sample,

$h$ - sample height before tests,

$\Delta h$ - subsidence of the sample as a result of stress change by $\Delta \sigma_{i}$.

\section{Proposed modified method of testing}

Modified testing equipment can ensure consideration of vibration impact on soil strength parameters. It should take into account transition of vibrations from the equipment to the 
tested soil sample. Such equipment was described in [4] and tested with success [5] with respect to sand, proving impact of vibrations on its strength. The range of amplitudes and frequency of vibrations applied at tests should reflect their parameters determined by measurements or expected for natural conditions. The same approach could be used to consider increase in subsidence caused by vibrations.

\subsection{Modified tests with immediate shearing test apparatus}

When there is a possibility for dynamic vibration to occur, one can determine their influence upon soil strength with use of methodology described in 3 with the following modifications to interaction (1):

$$
\tau_{t}^{\prime}=\sigma^{\prime} \cdot \operatorname{tg} \phi_{t}+c_{t}
$$

where: $\quad \tau_{t}^{\prime}$ - resistance of the soil against static stress under dynamic vibrations

$\sigma^{\prime}$ - effective normal stress,

$\phi_{t}^{\prime}$ - effective internal friction angle with consideration of the effect of dynamic vibrations,

$c_{t}^{\prime}$ - effective cohesion with consideration of the effect of dynamic vibrations,.

It is therefore possible to determine minimal values $\phi_{t}^{\prime \min }$ and $c_{t}^{\prime \text { min }}$ for a number of tests with forced vibrations of various amplitudes and frequencies. When the obtained results are compared to soil strength parameters $\phi^{\prime}$ and $c^{\prime}$, determined for soil not subjected to vibrations, one can reach a coefficient to correct the obtained results in a typical way (with no vibrations used). A coefficient of vibration impact $v$ can be a measure of potential influence of these vibrations on ground and its strength, and it is determined from the following interaction:

$$
v=\frac{\sigma^{\max } \cdot \operatorname{tg} \phi_{t}^{\min }+c_{t}^{\prime \min }}{\sigma^{\prime \max } \cdot \operatorname{tg} \phi^{\prime}+c^{\prime}} \leq 1
$$

where: $\quad \phi_{t}^{\prime \min }, c_{t}^{\prime \min }-$ minimum values of effective friction angle and cohesion, from all tests,

$\phi^{\prime}, c^{\prime}$ - effective internal friction angle and cohesion characteristic of soil not subjected to dynamic vibrations,

$\sigma^{\prime \max }$ - maximum value of normal effective stress used in test.

The therefrom determined coefficient $v$, used for the shear strength determined in tests, allows to consider its decrease as a result of vibrations initiating thixotropy ( $\phi^{\prime}$ and $c^{\prime}$ are multiplied by coefficient $v$ ). It can be assumed that, as the author suggests, soils with relation to vibrations remain insensitive $(v=1)$, slightly sensitive $(1>v \geq 0.8)$, sensitive $(0.8>v \geq 0.5)$ and very sensitive $(v<0.5)$.

\subsection{Modified oedometric test of soil compression}

As a result of vibrations in the vicinity of a structure, additional deformations related to soil thickening in response to them can be observed. It is possible to take the phenomenon into account in laboratory tests. To do so one needs to apply an apparatus modelling close to natural dynamic vibrations in soil compression oedometer. The following interaction is then obtained:

$$
\xi=\frac{M_{t}^{\min }}{M}=\left(\frac{\Delta \sigma \cdot h}{\Delta h_{t}^{\max }}\right):\left(\frac{\Delta \sigma \cdot h}{\Delta h}\right)=\frac{\Delta h}{\Delta h_{t}^{\max }} \leq 1
$$

where: $M-$ oedometric compression module determined with no vibrations used, 
$M_{t}^{\text {min }}$ - minimal oedometric compression module for various vibration types,

$\Delta h \quad$ - change to sample height caused by increase in stress by $\Delta \sigma$ without vibrations,

$\Delta h_{t}^{\max }$ - maximum change of sample height as a result of change in stress by

$\Delta \sigma$ and for dynamic vibrations of various parameters,

$\xi$ - coefficient of dynamic vibrations impact on soil subsidence .

The range of tested values $\Delta \sigma$ and related $\Delta h$ need to be determined for adequate sections of primary and secondary cohesion curve. The same $\Delta \sigma$ intersections should be applied for test results with and without dynamic vibrations impact.

Coefficient $\xi$ should be used to determine subsidence in soils susceptible to dynamic vibrations. The calculated subsidence values for soil not subjected to dynamic vibrations should be divided by the coefficient $\xi$.

\section{Conclusions}

Vibrations occurring in water saturated soils have two sorts of unfavourable effects; they cause decrease in shear strength and increase in subsidence. This happens because of restructuring of ground structure, especially in soils susceptible to thixotropy or fluidization. A method modifying course of laboratory tests has been proposed to take the above phenomena into account. It considers using forced vibrations to test shear strength and compression of soil which is especially useful for bedded grounds. The proposed method allows to measure and classify given soil with regard to its susceptibility to fluidization and thixotropy as well as self -thickening, caused by dynamic vibrations. The hereby described coefficients allow to take into account weakening of ground as a result of possible dynamic vibrations in soils susceptible to thixoctropy, fluidization or selfthickening, at the time its stability is being calculated. The method allows to determine the indirect values of ground strength parameters with consideration of measured or potential dynamic vibrations. It also makes it possible to determine the values of strength parameters by means of analogies with use of coefficients taking into account the least favourable impact of dynamic vibrations.

\section{References}

1. B. Fatahi, S. Tabatabaiefar S, Effects of Soil Plasticity on Seismic Performance of Mid-Rise Building Frames Resting on Soft Soils, Advan. in Struct. Eng. 17, 1387 (2014)

2. D. Park, B. Kutter, J. DeJong, Effects of Thixotropy and Cement Content on the Sensitivity of Soft Remolded Clay, Journ. of Geotech. and Geoenv. Eng. 141, 2, DOI: 10.1061/(ASCE)GT.1943-5606.0001221, (2015)

3. D. Park, B. Kutter, Static and seismic stability of sensitive clay slopes, Soil Dynam. Earthqu. Engin. 79, 118 (2015)

4. A. Taslagyan, D. Chan, N. Morgenstern, A Direct Shear Apparatus With Vibrational Loading, Geotechnical Testing Journal 38, 1 (2015)

5. A. Taslagyan, D. Chan, N. Morgenstern, Effect of vibration on the critical state of dry granular soils, Granular Matter, Springer 17, 687 (2015)

6. J. Ukleja, Geotechniczne aspekty stabilizacji obszarów zagrożonych osuwiskami, (Ofic. Wyd. Pol. Opol. , Studia i Monografie, 369, Opole, 2013)

7. Z. Wiłun: Zarys geotechniki, (Wyd. Kom. i Łączn., Warsaw 1982) 